\title{
L La información del Patrimonio Histórico Andaluz en Internet
}

\author{
Carmen Ladrón de Guevara Sánchez \\ Jefa del Centro de Documentación del IAPH
}

El diseño, producción e implantación de un acceso temático especializado en patrimonio histórico a través del servidor web del IAPH es un proyecto en el que se ha venido trabajando en el Centro de documentación durante estos últimos seis meses. Los objetivos que hemos querido cubrir son múltiples, pero principalmente se trata de diversificar la presentación del patrimonio histórico utilizando lenguajes comunicativos diversos a través de las redes de comunicación.

El proyecto ha nacido con la participación de un equipo multidisciplinar' del Centro de documentación. Su objetivo inicial es dar salida a la información existente en el mismo, tratada y presentada para la red; pero en una segunda fase se tiene previsto la participación de otras instituciones.

La configuración que se le ha dado pretende ser dinámica, intuitiva, versátil con objeto de dar una oferta rica y variada de la información existente a los usuarios de la red. Así a lo largo de todas las páginas aparecerán imágenes, textos y datos integrados en un equilibrio que esperamos no canse al espectador.

\section{Página principal}

La página principal (Fig. I) se ha elaborado con un diseño que huye de la estructura jerárquica de la información pretendiendo sugerir accesos alternativos según el nivel de profundidad que se quiera alcanzar en un momento determinado.

De esta manera se ofrece información a distintas escalas, en distintos formatos, facilitando al usuario la elección de uno u otro camino desde un primer nivel sin necesidad de profundizar demasiado en la navegación.

Se ofrecen ocho accesos iniciales:

I. Presentación Patrimonio Histórico

2. Territorio y Patrimonio

3. Productos de Información

4. Base de Datos Patrimonio Histórico de Andalucía

\section{Textos-e}

6. Banco de Imágenes

7. Otras Visiones

8. Servicios de Información

Este panorama no agota todos las posibles opciones de presentación del patrimonio histórico de Andalucía. Hemos huido de una estructura jurídica, tipológica o disciplinar. Todas estas visiones se encuentran recogidas en el contenido de los distintos accesos.

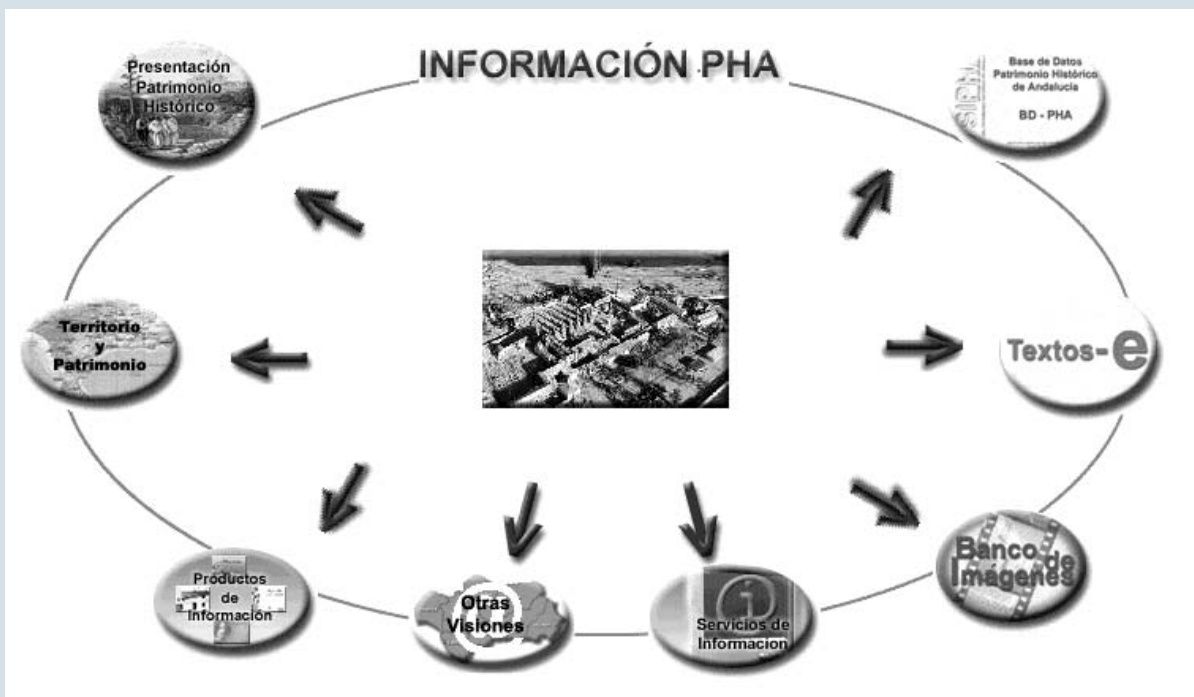




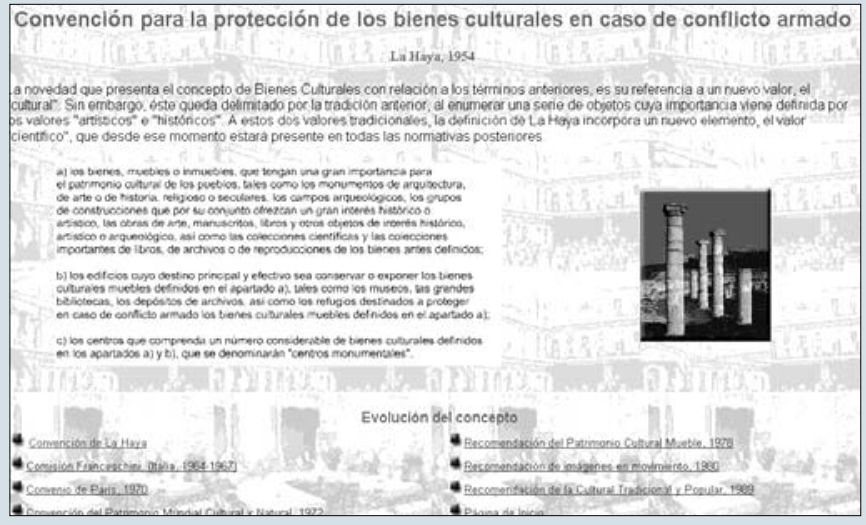

Figura 2

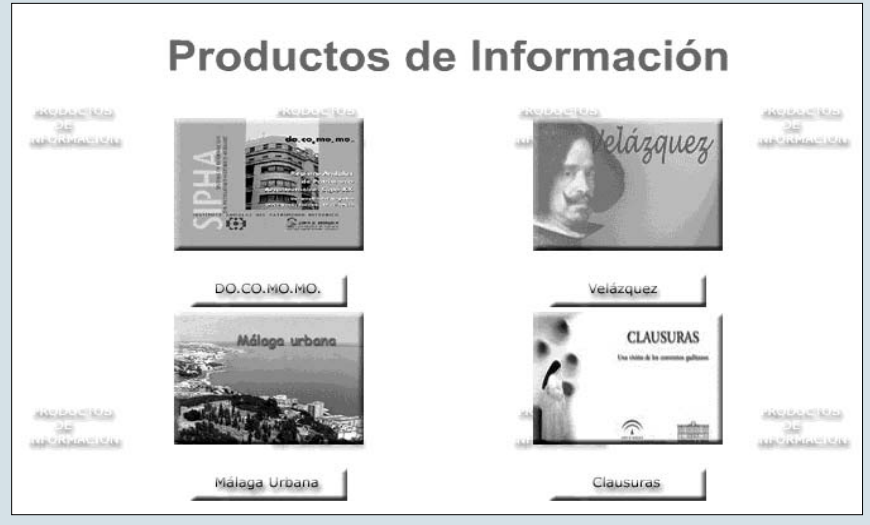

Figura 3

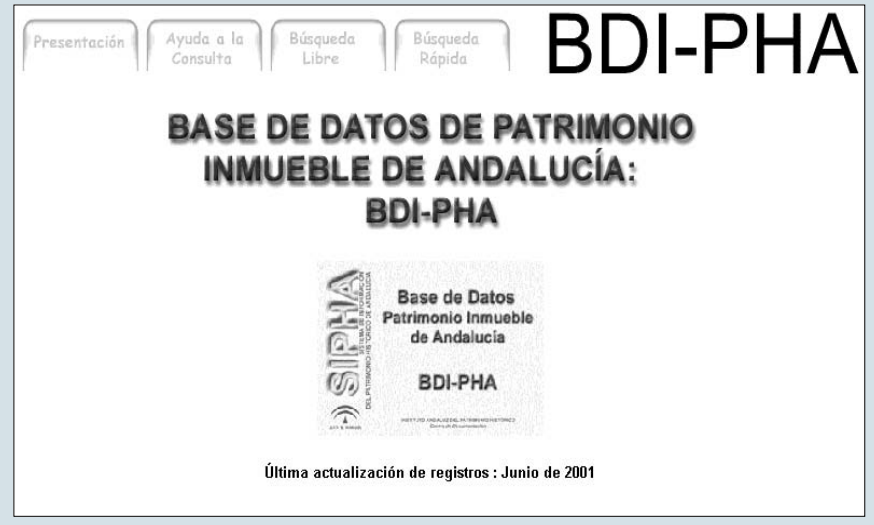

Figura 4

Mas bien hemos querido conjugar aspectos más reflexivos con otros más visuales; facilitar el acceso a los servicios de información y a la vez ofrecer la consulta on-line de los datos y asimismo facilitar el enlace con otras visiones que de nuestro patrimonio se tenga en otras páginas webs, lo que ha supuesto una gran labor de búsqueda y selección de las mismas.

Este proyecto se entiende como algo abierto. Nuestro resto es la actualización de la información y el enriquecimiento permanente de la misma.

\section{Presentación Patrimonio Histórico}

Un breve recorrido (Fig. 2) a través de la evolución del concepto de patrimonio histórico, desde el concepto de "tesoro artístico", "monumento histórico artístico", etc... hasta el actual de "bien cultural", analizando aquellos foros en los que se ha ido debatiendo dicha evolución conceptual. Asimismo se analizarán las distintas categorías, clasificaciones y normas jurídicas que lo tutelan, con objeto de tocar aquellos aspectos que el resto de los accesos van a dar por conocido.

\section{Territorio y Patrimonio}

Inicialmente lo que presentamos es un análisis cuantitativo de distintas variables que caracterizan a nuestro patrimonio cruzado con su localización espacial. Se ha resuelto en esta primera fase mediante un mapa sensible de Andalucía que muestra el patrimonio inmueble de las distintas provincias andaluzas.

Visualmente puede sugerir lecturas distintas necesitadas para su interpretación de un análisis en profundidad. Pero es el comienzo de un camino, que pretendemos continuar presentando conforme se vayan completando los análisis y se vayan obteniendo resultados

\section{Productos de Información}

Este acceso pretende dar cabida a aquellas producciones que presenten específicamente el patrimonio histórico andaluz (Fig. 3); se encontra- rán productos monográficos sobre un determinado bien cultural, sobre un artista, itinerarios culturales, etc. Su producción será en unos casos específica para este medio y su justificación podrá venir dada por la oportunidad de la celebración de un evento, etc.; En otros casos serán producto de la conversión de los CD-ROM temáticos producidos por el Centro de documentación, tales como: "Clausuras de Cádiz", etc.

\section{Bases de Datos Patrimonio Histórico de Andalucía}

Tras la puesta en marcha de los servicios de información, que han servido de salida de la información de las bases de datos de patrimonio histórico desarrolladas por el Centro de documentación y la buena acogida que han tenido por parte de los usuarios, era deseable ofrecer un acceso directo a los datos a través de su consulta on-line (Fig. 4). Esto es lo que ofrece este acceso para todos aquellos que requieran un nivel básico del patrimonio histórico protegido en Andalucía. En esta fase los datos que se ofrecen son los de patrimonio inmueble. 


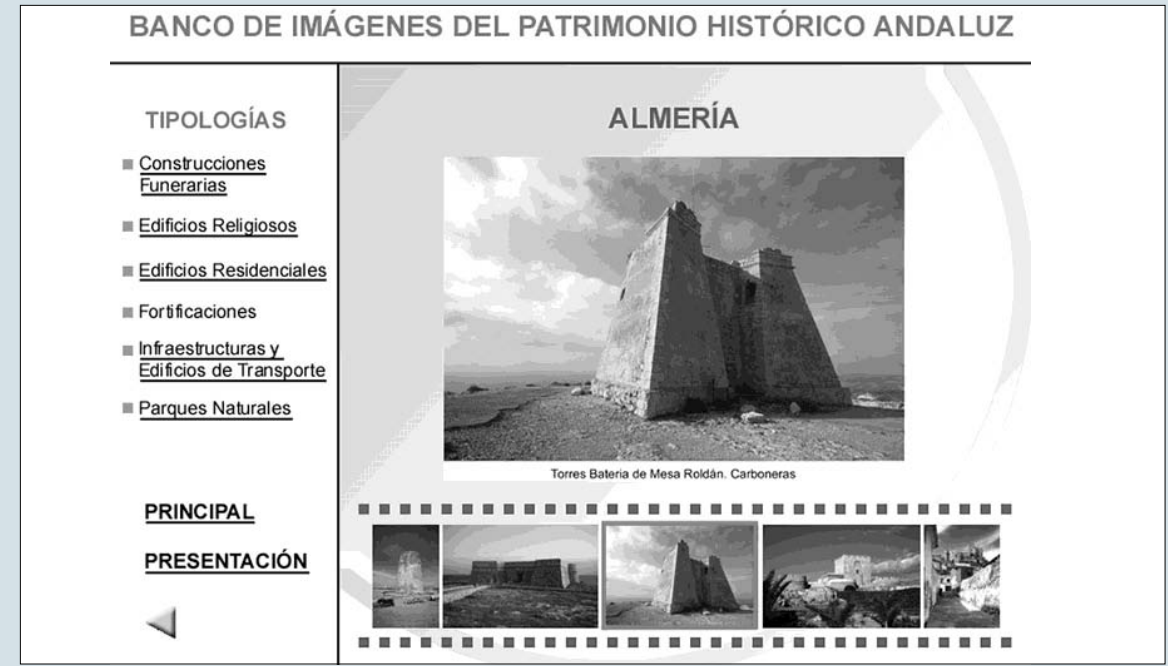

Figura 2

\section{Textos-e}

Se presentan en formato electrónico (Fig. 5) los textos de la Sección "Información: Patrimonio Histórico Andaluz" del Boletín del Instituto Andaluz del Patrimonio Histórico con el fin de acercarlos a aquellos que no tienen acceso a dicho boletín. En dicha sección se presenta el patrimonio histórico andaluz desde perspectivas menos tratadas tradicionalmente en un intento de cubrir esas carencias con las aportaciones de los estudios y reflexiones de los profesionales mas expertos en las mismas. Hemos considerado, pues, de interés su divulgación a través de este medio por el mayor alcance que ofrece en sí mismo. de Andalucía en el que a través de un acceso geográfico se accede a una organización tipológica con objeto de facilitar la consulta de las imágenes de nuestro patrimonio. Lo que se presenta es una selección de las imágenes mas representativas del fondo gráfico, a sabiendas que no todas las provincias ni

\section{Otras Visiones}

Facilitar a nuestros usuarios otras perspectivas de nuestro patrimonio a través de enlaces temáticos a otras webs es el objetivo de este acceso. Supondrá para el usuario un enriquecimiento en el conocimiento de nuestro patrimonio, una multiplicidad de perspectivas desde otras instituciones, profesionales, etc... que completará la información ofrecida en nuestra web. Su diseño, actualmente en ejecución, se ha concretado en un mapa web de Andalucía en el que a través de un primer nivel de acceso geográfico se accede a niveles temáticos de agrupación de las sedes webs seleccionadas.

\section{Servicios de Información}

A través de este acceso se puede realizar una demanda de información mediante la cumplimentación del formulario electrónico y a la vez tener acceso a las estadísticas elaboradas de los años 2000, 1999 y 1998 que presentan el volumen de demandas recibidas, la procedencia de nuestros usuarios etc. y asimismo conocer el alcance de nuestros recursos de información. todas las tipologías tienen el mismo nivel de representatividad.
Con esta breve presentación hemos querido reseñar este nuevo proyecto y exponer mínimamente su contenido y sus objetivos. Ahora lo que queda es esperar a ver la acogida que tiene $y$ en ediciones sucesivas iremos profundizando en el alcance de cada acceso.

I. Con posterioridad se irán publicando por parte de los miembros del equipo los comentarios acerca de sus elaboraciones propias.

\section{La página web del Ayuntamiento de Écija}

Es evidente, hoy en día, que la presencia en Internet es cada vez más necesaria para llegar a un público masivo y tener la posibilidad de ser conocidos fuera de nuestras fronteras. $\mathrm{Si}$ a esto añadimos la importancia que está tomando el turismo cultural fuera de las grandes capitales, y la mayor concienciación general que se está tomando en el ámbito de la conservación patrimonial en todas sus facetas, es aún más necesario dedicar un espacio en la red para dar a conocer el patrimonio más desconocido y olvidado de nuestra geografía, y que éste sea un incentivo para que a través de dicha información exista un público interesado en visitar y conocer esos lugares que no por lejanos resultan ser de menos entidad cultural y monumental.

Esto ocurre con algunos pueblos andaluces de los que encontramos en Internet páginas web de gran utilidad informativa. Ejemplos como los de Carmona o el de Écija nos ayu- dan a conocer con detalle los elementos que conforman su identidad cultural y patrimonial. En esta ocasión, analizaremos la página web que el ayuntamiento de Écija dedica a la comúnmente llamada ciudad de las torres.

La página de inicio está planteada como un portal con múltiples opciones de entrada de muy variada naturaleza, pero todas ellas con un único objetivo común: servir de puerta de acceso a los servicios municipales y a una 